\title{
CORRIGENDUM
}

\section{Theory of Mind in Children with Traumatic Brain Injury - CORRIGENDUM}

M. Dennis, N. Simic, H.G. Taylor, E.D. Bigler, K. Rubin, K. Vannatta, C.A. Gerhardt, T. Stancin, C. Roncadin, AND K.O. Yeates

doi:10.1017/S1355617712000756, Published by Cambridge University Press, June $30^{\text {th }}, 2012$

In the article "Theory of Mind in Children with Traumatic Brain Injury", by Dennis et al., 2012, the description of participants in the study was inaccurate as published. In the description of inclusion/exclusion criteria for the studies of social outcomes in children with TBI, all of our participants were at least 12 months post injury when they participated (not 6 months post injury as was written), and they were up to 63 months post-injury when they completed Visit 1 (not 48 months as written). The authors regret the error.

\section{REFERENCE}

Dennis, M. et al. (2012). Theory of mind in children with traumatic brain injury. Journal of the International Neuropsychological Society, 18, 908-916. doi:10.1017/S1355617712000756 